\title{
The recovered female ex-offenders
}

\author{
Hui-Ching $\mathrm{Wu}^{1 *}$ and Huang Ming-Chi ${ }^{2}$ \\ ${ }^{1}$ Department of Social Work, National Taiwan University, Taipei, Taiwan \\ ${ }^{2}$ Department of Addiction Sciences, Taipei City Psychiatric Center, Taipei City Hospital, Taipei, Taiwan
}

\section{Introduction}

Recovery for ex-offenders is currently one of the major issues in the criminal justice, health care and social services providers, especially for the drug use offenders, promoting a successful recovery is an ongoing concern in efforts to reduce recidivism [1]. Especially for the female, they are the fastest-growing population in the criminal justice system, and jails reach more people than any other component of the correctional system. In addition to stopping drug use, the goal of recovery is to return people to productive functioning in the family, workplace, and community as well as to maintain a normal lifestyle and social contacts. Many of ex-offenders struggled with the dynamic process of the ultimate goal of community recovery that is a long-term journey [2] and would have experienced several challenges.

Typically, ex-offenders experienced wide-ranging challenges to reintegrate into the society that were conceptualized in three domains: intrapersonal conditions (e.g. physical and psychological health state, substance use, education and social skills); subsistence conditions (e.g. finance, employment, and housing); and support conditions (e.g. social/ health care/criminal justice services, new social networks, informal support) $[1,3]$. These challenges make most ex-offenders re-enter the communities within a few weeks of arrest, and few receive help for the substance abuse, health, psychological or social problems that lead to incarceration [4].

Hence, the process of recovery depends on both the woman's developing a sense of self-efficacy and her strategic use of family, correctional, and community resources [5] to help successful recovery. To identify the predictors of recovered ex-offenders would contribute to develop the strategies to help them change the behavior and the conditions of their lives by reducing the drug use, improving the health, avoiding dangerous relationships, increasing social capacities for life. The domains of aggressive social participation and individual recovery reflect from the satisfactory with quality of life.

Researchers identified numerous influential variables related to success in recovery processes such as social support [6,7], employment $[8,9]$, the absence of family conflicts $[10,11]$, medium-high educational level $[9,10]$, lack of addiction by the parents [10], no consuming alcohol or types of drugs $[11,12]$, the absence of previous treatments and mental health problems [10] and less correctional records, regarding length of the sentence, number of previous prison admissions, age at the first entry and other indicators [9]. Especial for women, motivation to reclaim custody of their children is an enabling factor of success [7].

\section{The bio-psycho-social differences}

The manifestations of recovery involved women are different from that of men, particularly related to mental and physical health, health risks, occupational engagement and economic security, social relationships, family issues and natal care [13,14]. Female drug addicts are even worse to be doubly stigmatized in society, given that they are not only breaking the law, but also their gender obligations. Prevalence of sexual exploitation and abuse during childhood is higher in women too. Moreover, stigmatization of women drug addicts and / or imprisoned make them less supported than men in the same situation. Women suffered greater difficulties in community reentry and recovery, but they may have more motivation to achieve it of being a role of family caregiver [15]. The key differences between male and female drug users were categorized into physical, environmental, and psychological aspects [16-18]. Physically, due to the influence of gonadal hormone estrogen and a higher percentage of fat in the female body makeup compared with males, females were found to be more vulnerable to being affected by substance usage [19]. Environmentally, more female substance users have suffered from traumatic experiences $[20,21]$, a dysfunctional family [22], sexual abuse and assault [23,24], domestic violence [25], and physical and emotional abuse in their early childhood [24] than male substance users. Psychologically, female substance users were found to present more likely to feel depression [22] and to have low self-esteem [26-28], low impulsive control, and weak emotional management skills $[29,30]$ than male substance users.

The feelings of environmental and psychological distress would associate with disempowerment and worthlessness among women, the tone is to set up for pursuing something that increase one's sense of being in control and values. Facing the life challenges, the gender reacts differently between coping styles and substance abuse [31]. Effective coping is consistently cited as a key ingredient in relapse prevention, and as such, it has often been targeted as a component of treatment interventions and preventions. Female were more likely to use substitution (engaging in tension-reducing activities) and reversal (acting the opposite of one's feelings) than mapping (collecting information about the problem or problem solving).

\section{Coping, social support and empowerment}

Coping is a basic human competency and recognized as one of the most essential personal skills that impacts upon the quality of an individual's social functioning [32]. Coping mechanisms have been defined as action-oriented and intrapsychic efforts to manage (i.e., master, tolerate, reduce or minimize) environmental and interpersonal demands and conflicts [33] or as cognitive, behavioral and emotional

*Correspondence to: Hui-Ching Wu, Department of Social Work, National Taiwan University, No. 1, Sec. 4, Roosevelt Road, Taipei, Taiwan, E-mail: hchingwu@ntu.edu.tw

Received: October 23, 2019; Accepted: October 29, 2019; Published: October 31, 2019 
strategies used to manage external distress, threats, and/or internal tension or eliminate stressors [34]. Individuals' coping strategies are of critical importance in understanding substance use. Substance use itself is sometimes considered a maladaptive, negative or avoidant coping strategy and may be used to develop as a disorder. The vulnerable female tends to seek for a source of external to the self, in this case, alcohol or drugs and to have a lifetime risk of substance use dependence $[35,36]$ and greater risk of relapse [37]. A higher use of adaptive coping strategies (e.g., active coping, positive reappraisal, emotional expression, and the ability to elicit social support), higher levels of optimism, mastery, and purpose in life, and lower use of avoidant coping strategies (e.g., denial, behavioral disengagement, substance use) to be associated with better recovery [38].

The individual would incline to seek out and interact with others as one strategy to moderate stress. Studies have documented the importance of social support for women $[39,40]$ and increased use of social support from significant others to be linked to better substance use outcomes [41]. Generally, the benefits of social support span practical, material help and emotional support that can contribute in powerful, important ways to assist individuals to deal with, and recover from, stress and distress. Social support system could be categorized as informal and formal social support system. The informal social support consists of family, carers in the family, friends, neighbors and colleagues, which provide information and other resources in a time of stress or crisis; the later including the support from health care, social services and justice system to provide the minimum care for the living (e.g. housing, crisis assistance allowance, health care, occupational training/ employment coordination). The women tend to place greater value on relationships that may be the result of their socialized dependency and trust (Abbott, 1994). However, the process of re-building relationship with family and restoring the trust are difficult and limited [42]. As a result, informal social support become an important resource in their recovery process, especially the support from significant others though might also be abstinent.

Many female ex-offenders felt disenfranchised and powerless to develop healthy, growth-producing lives. Due to fail to develop the basic social competencies in childhood through continuous interaction with the growing environment, women ex-offenders enter adulthood powerless [43], have a sense of distrust and hopelessness in the sociopolitical environment, feel alienated from resources for social influence, and are economically vulnerable [44]. Empowerment is central to the work of enhancing well-being and improving human lives $[45,46]$. Gaining control over the factors which are critical in accounting for one's state of oppression or disempowerment. It is widely agreed upon that empowerment processes encompass material resources and inequities in the environment, strengths of the individual and a sense of personal control, and the enhancement of well-being [47]. Empowering female ex-offenders is important to provide opportunities pursuing the equality of social attendance that contributes to the sense of recovery.

\section{Conclusion}

The female ex-offenders represent one group whose problem should be adequately understood or whose needs were encouraged to address. Greater attention must be given to the needs of women across the life cycle. The health care and social services system providers should have a dedicate evaluation after the female post-incarceration, especially on their life needs, mental health conditions, coping skills, criminal/ drug use history, informal support system building with the significant others and family, the accessibility and the availability of social services to empower them survival from the society. The interdisciplinary collaboration of the diverse services would be ascribed as an essential component. The continuing care and assistance in enhancing the education and occupational capacities would contribute to the female ex-offenders' recovery.

\section{References}

1. Shinkfield AJ, Graffam J (2009) Community Reintegration of Ex Prisoners: Type and Degree of Change in Variables Influencing Successful Reintegration. Int J Offender Ther 53: 29-42.

2. Visher CA, Travis J (2003) Transitions from prison to community: Understanding individual pathways. Annu Rev Sociol 29: 89-113.

3. Travis J, Solomon AL, Waul M (2001) From prison to home: The dimensions and conse- quences of prisoner reentry. Urban Institute, DC, Washington.

4. Richie BE, Freudenberg N, Page J (2001) Reintegrating Women Leaving Jail Into Urban Communities: A Description of a Model Program. J Urban Health 78: 290-303. [Crossref]

5. O'Brien CP, McLellan AT (1996) Myths about the treatment of addiction. Lancet 347 $237-240$

6. Garmendia ML, Alvarado ME, Montenegro M, Pino P (2008) Importance of social support in the permanence of abstinence from drug use. Medical Magazine of Chile 136: $169-178$

7. Rodríguez Kuri SE, Fernández Cáceres C (2014) Social insertion of drug users in rehabilitation. A qualitative study. Journal of Psychology p. 6.

8. Gallizo M (2007) Social reintegration of drug addicts admitted to prisons. Health and drugs $7:$ : 57-74.

9. Ramos V, Carcedo RJ (2012) Re-entry into prison of drug inmates released to a therapeutic community, based on variables prior to treatment, Addictions 24: 329-338.

10. Mavrou J (2012) The factors of protection, risk and prevention of relapses in the drug-dependent population: Socio-educational analysis of the community program of Proyecto Hombre in Granada and the Pyksida program in Nicosia ( $\mathrm{PhD}$ thesis). Editorial of the University of Granada, Granada.

11. Valero-Aguayo L, Ortiz-Tallo M, Parra-García MM, y Jiménez-Guerra M (2013) Evaluation of results and psychosocial profile of a program of rehabilitation of people with drug addictions. Annals of Psychology p. 29.

12. García J, Méndez MP (2014) Factors associated with the early abandonment of treatment of substance use disorders in an institution in Medellín, Colombia. Colombian Journal of Psychiatry 43: 7-17.

13. Belenko S (2006) Assessing Released Inmates for Substance-Abuse-Related Service Needs. Crime Delinquency 52: 94-113.

14. Tiffany ST, Friedman L, Greenfield SF, Hasin DS, Jackson R (2012) Beyond drug use: a systematic consideration of other outcomes in evaluations of treatments for substance use disorders. Addiction 107: 709-718. [Crossref]

15. Duffy P, Baldwin H (2013) Recovery post treatment: plans, barriers and motivators. Substance Abuse Treatment, Prevention, and Policy 8: 6.

16. Gerolamo AM (2004) State of the science: Women and the nonpharmacologica treatment of substance abuse. J Am Psychiat Nurses 10: 181-189.

17. Molidor CE, Nissen LB, Waatkins TR (2002) The development of theory and treatment with substance abusing female juvenile offenders. Child and Adolescent Social Work Journal 19: 209-225.

18. Shelton DL (2000) New study highlights gender's impact on addiction. American Medical News 43: 30.

19. Davis DR, DiNitto DM (1998) Gender and drugs: Fact, fiction, and unanswered questions. In McNeece CA, DiNitto DM (Eds), Chemical dependency: A systems approach. MA: Allyn \& Bacon, Boston pp: 31-56.

20. Hien D, Cohen L, Campbell A (2005) Is traumatic stress a vulnerability factor for women with substance use disorders. Clin Psychol Rev 25: 813-823. [Crossref]

21. Koenig LJCH (2004) Sexual abuse of girls and HIV infection among women: Are they related. In Koenig LJ, Doll LS, O'Leary A, Pequegnat W (Eds) From child sexual abuse to adult sexual risk: Trauma, revictimization, and intervention. American Psychological Association: DC, Washington pp: 66-92. 
22. Finnegan DG, McNally EB (1997) Chemically dependent lesbians and bisexual women: Recovery from traumas. Journal of Chemical Dependency Treatment 6: 87-107.

23. Baker DR (2001) Substance abuse and mental illness: unaddressed public health issues for women. $J$ Am Med Womens Assoc 56: 27-28. [Crossref]

24. Nyamathi A, Longshore D, Keenan C, Lesser J, Leake BD (2001) Childhood predictors of daily substance use among homeless women of different ethnicities. American Behavior Scientist 45: 35-50.

25. Najavits LM, Sonn J, Walsh M, Weiss RD (2004) Domestic violence in women with PTSD and substance abuse. Addict Behav 29: 707-715.

26. Dodge K, Potocky M (2000) Female substance abuse characteristics and correlates in a sample of inpatient clients. J Subst Abuse Treat 18: 59-64.

27. Messina N, Prendergast ML (2001) Therapeutic community treatment for women in prison: Some success, but the jury is still out. Offender Substance Abuse Report 1: 49-58.

28. Sowards KA, O’Boyle K, Weissman M (2006) Inspiring hope, envisioning alternatives: The importance of peer role models in a mandated treatment program for women. Journal of Social Work Practice in the Addictions 6: 55-70.

29. Diamond J (2000) Narrative means to sober ends. Guilford: NY, New York.

30. Miller D, Guidry L (2001) Addictions and traumatic recovery. NY: Norton, New York

31. Paparrigopoulos T, Liappas J, Tzavellas E, Soldatos C (2007) Coping styles of alcoholdependent individuals: Comparison with depressed patients and controls. Soc Behav Personal 35: 599-614.

32. Valtonen K, Sogren M, Cameron-Padmore J (2006) Coping Styles in Persons Recovering from Substance Abuse. Brit Soc Work 36: 57-73.

33. Lazarus RS, Folkman S (1984) 'The concept of coping', in Lazarus, R. S. and Folkman, S. (eds), Stress, Appraisal, and Coping, Springer, New York, pp: 117-140.

34. Freire P, Moch K (1990) 'A critical understanding of social work', in Healey, K. (2000) Social Work Practices: Contemporary Perspectives on Change, Sage Publications, London.

35. Abbott AA (1994) A Feminist Approach to Substance Abuse Treatment and Service Delivery. Soc Work Health Care 19: 67-83.
36. Conrod PJ, Pihl RO, Stewart SH, Dongier M (2000) Validation of a system of classifying female substance abusers on the basis of personality and motivational risk factors for substance abuse. Psychol Addict Behav 14: 243-256. [Crossref]

37. Grella CE, Scott CK, Foss MA, Joshi V, Hser YI (2003) Gender differences in drug treatment outcomes among participants in the Chicago Target Cities Study. Eval Program Plann 26: 297-310.

38. Scarpa A, Haden SC, Hurley JD (2006) Community violence victimization and symptoms of posttraumatic stress disorder. The moderating effects of coping and social support. J Interpers Violence 2: 446-469.

39. Ashley OS, Marsden ME, Brady TM (2003) The effectiveness of substance abuse treatment programming for women: A review. Am J Drug Alcohol Ab 29: 19-53.

40. Litman GK, Stapleton J, Oppenheim AN, Peleg M, Jackson P (1984) The relationship between coping behaviours, their effectiveness and alcoholism relapse and survival. $\mathrm{Br}$ $J$ Addict 79: 283-291. [Crossref]

41. Litt MD, Kadden RM, Kabela-Cormier E, Petry N (2007) Changing network support for drinking: Initial findings from the Network Support Project. J Consult Clin Psych 75: 542-555.

42. EnglandKennedy ES, Horton S (2011) Everything that I thought that they would be, they weren't: Family systems as support and impediment to recovery. Soc Sci Med 73: 1222-1229. [Crossref]

43. Wilson MK, Anderson SCA (1997) Empowering female offenders: Removing barriers to community-based practice. Journal of Women and Social Work 12: 342.

44. Kieffer C (1984) Citizen empowerment: A developmental perspective. In J. Rapaport, C. Swift, \& R. Hess (Eds.), Studies in empowerment: Steps toward understanding and action, Haworth, New York, pp: 9-32.

45. Zimmerman MA (1995) Psychological empowerment: Issues and illustrations. Am J Commun Psychol 23: 581-599.

46. Sen AK (1999) Development as freedom. [1 ${ }^{\text {st }}$ Edn] Knopf, New York.

47. Cattaneo LB, Chapman AR (2010) The process of empowerment: A model for use in research and practice. The Am Psychol 65: 646-659. [Crossref]

Copyright: (O2019 Hui-Ching Wu. This is an open-access article distributed under the terms of the Creative Commons Attribution License, which permits unrestricted use, distribution, and reproduction in any medium, provided the original author and source are credited. 